\title{
Diagnóstico, perspectivas de uso e expansão dos serviços de trens metropolitanos no Brasil
}

\author{
Jonas Clemente dos Santos \\ Universidade Federal de Pernambuco \\ Marcos Felipe Falcão Sobral \\ Universidade Federal Rural de Pernambuco
}

\begin{abstract}
Os congestionamentos e as dificuldades de locomoção nos grandes centros urbanos têm desafiado os gestores públicos a encontrar soluções que favoreçam a mobilidade. Dentre as alternativas mais promissoras, encontra-se o uso do transporte ferroviário metropolitano (metrô) que, no Brasil, ainda está limitado a poucas capitais. Desta forma, o presente trabalho visa analisar o estado atual dos metrôs brasileiros. Foi realizada uma pesquisa de campo juntamente com a coleta de dados bibliográficos de forma a retratar a quantidade de linhas, estações e sua extensão, a quantidade de usuários, a mobilidade existente em relação a integrações com outros modais, os valores tarifários, os custos, investimentos e outras características. O estudo concluiu que todos os serviços apresentam dificuldades de expansão e deficiências nos serviços ao cliente e na comunicação com a sociedade.
\end{abstract}

Palavras-chave: mobilidade urbana; malha ferroviária; logística.

Diagnóstico y perspectivas de uso y expansión de los servicios de trenes metropolitanos en Brasil

La congestión y los problemas de movilidad en los grandes centros urbanos han desafiado los funcionarios públicos para encontrar soluciones que promuevan la movilidad. Entre las alternativas más prometedoras es el uso de la estación del metro (tren subterráneo) de que, en Brasil, todavía está limitado a unas pocas ciudades. Así, este estudio tiene como objetivo analizar el estado actual de los subterráneos de Brasil. Un estudio de campo se llevó a cabo junto con la colección de datos bibliográficos con el fin de retratar a la cantidad de líneas, estaciones y su extensión, los usuarios de cantidad, movilidad existente con respecto a la integración con otros modos, los valores tarifarios, costos, colocación y otras características. El estudio concluyó que todos los servicios tienen dificultades para ampliar y deficiencias en el servicio al cliente y la comunicación con la sociedad.

Palabras clave: movilidad urbana; red ferroviaria; logística.

http://dx.doi.org/10.1590/0034-76121529

Artigo recebido em 7 abr. 2013 e aceito em 18 dez. 2013.

Rev. Adm. Pública - Rio de Janeiro 48(2):481-506, mar./abr. 2014 
Evaluation, prospects of use and expansion of services regarding metropolitan trains in Brazil Congestion and transit problems in the urban centers have challenged public managers to find solutions that encourage mobility. Among of the most promising alternatives, is the use of rail metro (subway). Several cities around the world have used subway systems in order to equalize mobility problems, however, in Brazil, the use of this transport is still limited to a few capitals. Thus, this study aims to analyze the current state of the Brazilian Subway System. We conducted a field survey, along with the collection of bibliographic data in order to depict the amount of lines, stations and its extension, the quantity of users transported and the mobility of citizens in relation to existing integrations with other modes, the fares, costs investments and expandability. The study concluded that all services have difficulties to expand their rail network as well as deficiencies in customer service and communication with society.

KEYWORDs: urban mobility; railroad; logistics.

\section{Introdução}

A questão da mobilidade urbana tem sido objeto de diversos estudos que buscam caminhos para movimentação da população dentro de um determinado centro. Diversas propostas e soluções são descritas na literatura, tais como o uso compartilhado de veículos (Ohta et al., 2013), uso de táxis (Haque, Chin e Debnath, 2013) e transportes férreos em nível urbano (Niedzielski e Malecki, 2012).

No Brasil, existem diversas regiões metropolitanas que sofrem com congestionamentos oriundos do transporte rodoviário urbano. No cotidiano dos grandes centros urbanos é comum que fatores como superlotação de ônibus e trânsito de veículos médios e pequenos transformem a locomoção urbana em um problema com impactos econômicos e sociais.

Um dos transportes com a melhor relação custo benefício está sobre os trilhos e é convencionalmente chamado de metrô, quando usado em áreas urbanas. $\mathrm{O}$ uso do modal ferroviário para transporte urbano de pessoas se justifica por diversos aspectos, tais como o melhor controle de fluxo e o volume de pessoas carregadas por batelada, que chega a ser dezenas de vezes superior aos ônibus.

Apesar das vantagens inerentes a este tipo de modal, os investimentos para instalação ou ampliação de malha ferroviária urbana são extremamente elevados, o que inibe o uso desse tipo de transporte em muitas regiões.

Neste contexto, o presente tabalho relata uma pesquisa realizada entre 2012 e 2013 que diagnosticou o estado das malhas ferroviárias que estão em operação no Brasil.

Buscou-se analisar a quantidade de linhas, estações e a extensão de cada metrô em operação no Brasil. A pesquisa também levantou o volume de cidadãos transportados e a mobilidade existente em relação a integrações com outros modais, os valores tarifários, os custos com manutenção e com pessoal, dentre outros.

A pesquisa foi conduzida por meio de questionários direcionados aos gestores e de pesquisas junto aos bancos de dados de acesso à informação, visando oferecer um histórico e 
um diagnóstico detalhado de cada uma das linhas de metrô que estão em operação no Brasil. Como resultado, é possível observar as principais vantagens e deficiências de cada um dos sistemas de metrô, o que pode direcionar ações futuras para conduzir melhorias nesse estratégico modal de transporte urbano de massa.

\section{Referencial teórico}

A demanda por mobilidade é atualmente um componente crucial no debate sobre o desenvolvimento urbano (Camagni, Gibelli e Rigamonti, 2002). A mobilidade em áreas urbanas está atingindo seus limites e tem causado uma crescente demanda para os sistemas de transporte (Texas A\&M Transportation Institute, 2012). Assim, os sistemas viários tradicionais estão sofrendo grandes congestionamentos, fazendo com que a acessibilidade dos centros urbanos se deteriore (Nes e Bovy, 2004), inclusive em países com boa infraestrutura para uso de automóveis (Kuhnimhof et al., 2012; Millard-Ball e Schippe, 2010).

Além desses desafios, as mudanças nos padrões de mobilidade urbana de pessoas, as mudanças demográficas e a redução da capacidade de investimento das autoridades públicas precisam ser consideradas (Spickermann, Grienitz e Von Der Gracht, 2013).

A mobilidade proporcionada pelo transporte público facilita o aperfeiçoamento profissional contínuo das pessoas, o lazer, o acesso a equipamentos de saúde, centros culturais, dentre outros (Silveira e Cocco, 2013). Além disso, o perfil de tarifas possui um poder simbólico, quando relacionado ao transporte público (Rosa Filho, 2011).

Uma medida para lidar com as restrições de mobilidade urbana é promover o transporte público (Spickermann, Grienitz e Von Der Gracht, 2013). Os sistemas de transporte têm diferentes implicações e exigem características específicas para a operação bem-sucedida (MejíaDugand et al., 2013).

No transporte público é possível se trabalhar com múltiplos modais de transporte. Diversas propostas de modais de transporte público têm sido implementadas, dentre as quais:

a) Bus Rapid Transit (BRT): é um sistema de transporte baseado em ônibus, que opera em corredores isolados do trânsito tradicional. O BRT está ligado a um complexo conjunto de atores e redes dentro das dimensões técnicas e sociais da cidade (Mejía-Dugand et al., 2013).

b) Veículo Leve sobre Trilhos (VLT): é um modelo de transporte sobre trilhos que utiliza veículos menores que o metrô convencional. Oferece um bom nível de confiabilidade e conforto, apesar de não melhorar substancialmente o transporte público (Kim e Ulfarsson, 2012).

c) Trens Metropolitanos (Metrô): é adotado para transporte de massa, em estruturas isoladas dos demais modais de transporte urbano. 
Um possível benefício de sistemas de trens metopolitanos é a conexão entre as regiões periféricas e as regiões de oferta de trabalho. Os efeitos de desenvolvimento econômico de um sistema ferroviário rápido podem ocorrer em nível regional ou em nível local (Bollinger e Ihlanfeldt, 1997).

O transporte por meio de sistemas de metrô se tornou uma importante ferramenta para a mobilidade de massa nas cidades. Evidentemete que a implantação de sistemas de trens urbanos demanda altos investimentos, porém é possível observar ganhos sociais atrelados ao uso do metrô. Dessa forma, no contexto de uma avaliação econômica, um projeto de transporte pode ser considerado de interesse para a sociedade ainda que não gere o retorno financeiro exigido pelo investidor privado (Dalbem, Brandão e Macedo-Soares, 2010).

\section{Histórico da malha ferroviária brasileira}

O século XIX foi marcado pelo desenvolvimento de malhas ferroviárias em diversas capitais do mundo (Bladen, 1934). Acompanhando esta tendência, o Brasil, ainda na época do Império, iniciou em 1828 diversas iniciativas para viabilizar a operacionalização das locomotivas (Dnit, 2013). Em 1835, o governo imperial assinou uma lei permitindo que qualquer companhia construísse uma ou mais estradas de ferro que ligassem o Rio de Janeiro, Minas Gerais, Rio Grande do Sul e Bahia, além de conceder privilégios para prestar seus serviços (Dnit, 2013).

A primeira ferrovia foi construída pelo empreendedor brasileiro Irineu Evangelista de Souza, também conhecido como barão de Mauá, em 1852, no trecho entre Rio de Janeiro e Porto de Estrela (Barman, 1981). Em 1853 foi organizada a Empresa Recife and São Francisco Railway Company, ligando o Recife ao rio São Franciso, e que iniciou suas operações em 1858, sendo reconhecida como a segunda estrada de ferro a entrar em operação no Brasil (Setti, 2008).

Em 1922, o sistema ferroviário brasileiro contava com cerca de 2 mil locomotivas a vapor e 30 mil vagões, atingindo a marca de 29 mil quilômetros de extensão (Dnit, 2013). Em um intervalo de tempo de menos de 30 anos, a malha ferroviária brasileira passou a ter 37 mil quilômetros de extensão (Dnit, 2013). A partir de 1950, iniciou um processo de unificação das 42 ferrovias existentes no Brasil, formando 18 estradas de ferro (Dnit, 2013).

Em 1957 foi criada a Rede Ferroviária Federal Sociedade Anônima (RFFSA), através da consolidação de 18 ferrovias regionais (RFFSA, 2013). A RFFSA esteve em operação durante 40 anos, atendendo diretamente a 19 unidades da Federação, em quatro das cinco grandes regiões do país, operando uma malha que, em 1996, compreendia 22 mil quilômetros de linhas (RFFSA, 2013). A RFFSA foi incluída em 1992 no Plano Nacional de Desestatização, sendo dissolvida no mesmo ano e extinta em 2007 (RFFSA, 2013). Com a desestatização, os ativos operacionais foram concedidos por 30 anos para a iniciativa privada. A tabela 1 demonstra a distribuição das malhas.

Atualmente existem alguns projetos para implantação e renovação da malha ferroviária. Dentre eles está o projeto de implantação de um trem de alta velocidade ligando as 
cidades do Rio de Janeiro e São Paulo, com um investimento aproximado de R\$18 bilhões (ANTT, 2013).

$$
\text { Tabela } 1
$$

\section{Concessionárias de Transporte Ferroviário}

\begin{tabular}{|ccccc|}
\hline Malhas Regionais & Data do Leilão & Concessionárias & Início da Operação & Extensão $(\mathrm{km})$ \\
\hline Oeste & 5.3 .1996 & Ferrovia Novoeste S.A. & 1.7 .1996 & 1.621 \\
Centro-Leste & 14.6 .1996 & Ferrovia Centro-Atlântica S.A. & 1.9 .1996 & 7.080 \\
Sudeste & 20.9 .1996 & MRS Logística S.A. & 1.12 .1996 & 1.674 \\
Tereza Cristina & 22.11 .1996 & Ferrovia Tereza Cristina S.A. & 1.2 .1997 & 164 \\
Nordeste & 18.7 .1997 & Cia. Ferroviária do Nordeste & 1.1 .1998 & 4.534 \\
Sul & 13.12 .1998 & América Latina Logística S/A & 1.3 .1997 & 6.586 \\
Paulista & 10.11 .1998 & Ferrovias Bandeirantes S.A. & 1.1 .1999 & 4.236 \\
\hline
\end{tabular}

Fonte: RFFSA (2013), Dnit (2013).

Para fins urbanos, o uso do transporte ferroviário ocorreu de forma tardia no Brasil. A primeira iniciativa efetiva para uso do metrô para transporte urbano ocorreu em São Paulo em 1966, com a fundação da empresa gestora e início das obras (Metrosp, 2013).

Atualmente utilizam sistemas de metrô as cidades de Recife, Porto Alegre, São Paulo, Brasília, Belo Horizonte, Teresina e Rio de Janeiro e há projetos para instalação em Fortaleza, Natal, João Pessoa, Maceió e Salvador. Está em curso também uma parceria entre a Universidade Federal do Rio de Janeiro (UFRJ) e o Instituto Alberto Luiz Coimbra de Pós-Graduação e Pesquisa em Engenharia (Coppe) sobre a implantação de um trem que utiliza levitação magnética para transporte urbano de pessoas proposto e criado no Brasil (Maglev Cobra, 2013). Entretanto, a aplicação em larga escala ainda pode exigir pesquisas e investimentos adicionais.

\section{Metodologia e planejamento da pesquisa}

Este estudo utilizou pesquisas de caráter exploratório e bibliográfico. Foram colhidas informações contidas em banco de dados e documentos públicos disponíveis nos portais do governo, juntamente com questionários de cunho qualitativo. A consolidação dos dados contemplou o uso de documentação direta e indireta.

A pesquisa se iniciou em novembro de 2012 e durou ao todo cinco meses. Foram utilizados mecanismos de busca como o Portal da Transparência e os Portais dos Metrôs locais de modo a coletar informações já públicas. Para complementar o diagnóstico foi utilizada pesquisa tipo survey. No questionário foram formuladas 10 perguntas específicas, nove eram abertas e uma era de assinalar. 
Para construção do questionário foram levadas em consideração a distância que o metrô percorre e a quantidade de pessoas que cada metrô atende, de modo a verificar sua disparidade em cada cidade. Também foram abordadas questões relativas à manutenção e ao tempo de uso de seus trens, além da análise de dados financeiros, como o valor dos bilhetes, existência de lucro ou prejuízo, dentre outros.

O envio do questionário de entrevista foi realizado por e-mail ou Serviço de Atendimento aos Clientes, após contato prévio por telefone. A exceção foi o Metrô do Recife que, após contato telefônico, sugeriu que a entrevista fosse conduzida pessoalmente.

Por se tratar de uma população reduzida (apenas sete concessionárias), optou-se pela não utilização de amostras.

\section{Relato sobre o processo de contato com as concessionárias de metrô}

Após a criação do questionário foi elaborado um ofício descrevendo a pesquisa e enviado, juntamente com o questionário, por e-mail para cada metrô (São Paulo, Rio de Janeiro, Recife, Porto Alegre, Teresina, Belo Horizonte e Brasília). Apenas a Trensurb (Porto Alegre) respondeu as questões no primeiro contato.

Com a ausência de respostas por e-mail, foi utilizado o Serviço de Informação do Cidadão (SIC) com as cidades remanescentes, onde se obtiveram respostas eletrônicas iniciais de Brasília e São Paulo. O Metrô de Brasília se prontificou em responder com algumas condições, tais como a apresentação do documento de identidade, nome completo e um esboço do que seria o trabalho. Após o atendimento das condições, recebemos o retorno sobre o questionário. O Metrô de São Paulo, por sua vez, respondeu em um prazo razoável e com riqueza de detalhes em todas as questões levantadas, não deixando nenhum tópico em aberto.

Em Recife o contato se transformou em uma visita pessoal de um dos pesquisadores, quando ocorreu o encontro com o gestor de área e o esclarecimento de diversas questões. $\mathrm{O}$ questionário foi prontamente respondido pela Metrorec.

O Metrô de Teresina possui meios de comunicação extremamente deficientes e o único meio de contato encontrado em seu site foi do desenvolvedor da página. O seu portal carece de informações atuais para contato com o cidadão. O e-mail que foi enviado para o endereço indicado em sua página da internet é direcionado para o Web design que projetou a página. Obtivemos como resposta que não seria possível atender a solicitação.

Na cidade do Rio de Janeiro não foi obtida resposta de nenhum dos setores contatados. O questionário não foi respondido e, todas as vezes que fora tentado contato com o metrô, apenas era enviado de volta um link do site da organização falando de uma forma breve e resumida do histórico do metrô, nenhum desses dados sendo útil ao questionário. Não foi conseguido contato com o metrô de Belo Horizonte pela internet. Outras tentativas foram feitas por meio de ligações telefônicas, porém sem sucesso. 


\section{Demonstrativo dos dados obtidos e análise dos resultados}

Este capítulo é destinado a demonstrar os dados e informações obtidos por meio de questionários, entrevista e pesquisa bibliográfica. O capítulo está estruturado em oito tópicos dos quais sete se referem a um Metrô em específico: o Metrô do Recife (Metrorec), o Metrô de Porto Alegre (Trensurb), o Metrô de São Paulo (Metrosp), o Metrô de Brasília (METRODF), o Metrô de Belo Horizonte (METROBH), o Metrô do Rio de Janeiro (Metrorio) e o Metrô de Teresina (CMTP).

Em cada um destes subtópicos buscou-se manter uma estrutura padronizada que inicia com um breve histórico, suas características peculiares e análise dos resultados obtidos com os questionários ou com a entrevista. No último tópico é feita uma análise global de todos os resultados obtidos nos metrôs pesquisados e estudados.

\subsection{Metrorec - Metrô do Recife}

O projeto de instalação de um metrô na cidade do Recife data de 1982, quando foi iniciado o planejamento para que fosse realizada uma interligação entre as cidades que formam a Região Metropolitana do Recife. Porém, foi só em janeiro de 1983, através da Rede Ferroviária Federal S/A (RFFSA), que o Metrô do Recife (Metrorec) surgiu (CBTU/Metrorec, 2013).

A extinção da RFFSA promoveu a transferência das linhas férreas para o Metrorec através da Companhia Brasileira de Trens Urbanos (CBTU). Esta seria responsável apenas para transporte de pessoas em regiões urbanas.

O Metrorec terminou por absorver os trens de subúrbio de várias cidades do Nordeste, sendo responsável até 1995 pela gestão ferroviária nas cidades de Maceió (AL), João Pessoa (PB) e Natal (RN) (CBTU/Metrorec, 2013).

Por ter incorporado boa parte da malha da RFFSA, a Metrorec herdou uma série de linhas que haviam sido planejadas em outro contexto. Com isso, muitas das estações foram localizadas em regiões de demanda desbalanceada.

Devido ao aumento da população e do uso do Metrô de Recife, em 1998 foram iniciadas as obras de expansão a partir da Estação Rodoviária até a cidade de Camaragibe, que foram entregues à população em dezembro de 2002, e da Linha Sul que liga a Estação Recife até Cajueiro Seco, inaugurada em 23 de março de 2009 (CBTU/Metrorec, 2013).

Atualmente, o Metrô do Recife, que continua sendo administrado pela CBTU, liga diretamente as cidades do Recife, Cabo de Santo Agostinho, Jaboatão dos Guararapes e Camaragibe, além de também ter acesso indireto às demais cidades da Região Metropolitana do Recife através de integrações com ônibus.

Esse sistema sobre trilhos que interliga as cidades da Região Metropolitana do Recife (RMR) possui três linhas. São elas: a Linha Centro é uma linha eletrificada que parte da Estação Recife e tem uma bifurcação na Estação Coqueiral, onde um trecho liga com Camaragibe e outro com Jaboatão dos Guararapes; a Linha Sul também é eletrificada e liga a Estação Recife 
com Cajueiro Seco; e a Linha Sul diesel, que é composta por trens de tração a diesel e vai até o município de Cabo de Santo Agostinho partindo de uma integração com os trens eletrificados na Estação Curado (CBTU/Metrorec, 2013).

O Metrorec possui hoje 28 estações que percorrem 39,5 quilômetros de extensão das linhas eletrificadas e mais oito estações que somam mais 31,5 quilômetros de extensão dos trens a diesel, totalizando assim 36 estações e uma extensão de 71 quilômetros de linhas férreas. O sistema de Metrô do Recife transporta por dia cerca de 280 mil pessoas, tem uma média de 42,4 passageiros por quilômetro rodado na Linha Centro e de 17,3 na Linha Sul.

Dispõe também de um sistema de integração com 111 linhas de ônibus, e 89 dessas permitem acesso livre a toda região metropolitana com o pagamento de uma única passagem pelo Sistema Estrutural Integrado (SEI).

Neste Metrô existem dois tipos diferentes de bilhetagem: a bilhetagem unitária e a bilhetagem integrada. O bilhete unitário consiste em um único cartão válido para apenas um embarque e custa $R \$ 2,60$ cada. O bilhete integrado equivale a um cartão válido para múltiplos embarques, dependendo de quanto for sua recarga, os valores para embarque variam entre o Anel A que custa R\$2,25 cada embarque, e o Anel B, que custa R\$ 3,45.

O sistema de Metrô do Recife é totalmente de superfície e dispõe de 25 trens fabricados entre os anos de 1985 e 1986 e cada máquina possui entre 25 e 26 anos de utilização comercial. No segundo semestre de 2012 foi efetuada a compra de mais 15 trens para início de renovação e ampliação da frota, porém apenas três desses 15 trens comprados foram entregues. Os trens recebidos passaram por testes durante cerca de quatro meses e estão operando na Linha Sul eletrificada. Essa nova remessa de trens possui características dos Veículos Leves sobre Trilhos (VLT), que prometem ser mais rápidos e modernos, tendo um consumo bem menor de energia.

O Metrorec vê uma necessidade clara de construção de novas rotas, aumentando assim a malha de transporte de pessoas sobre trilhos, alcançando áreas distintas, aumentando o acesso ao metrô e facilitando o transporte por toda a região. Existem diversas expectativas de expansão da malha do Recife, conforme demonstrado no quadro 1.

Quadro 1

Expectativas de expansão do Metrô de Recife

\begin{tabular}{|lcl|}
\hline \multicolumn{1}{|c|}{ Linha } & Implantação ou Ampliação & Fase \\
\hline Linha Norte-Sul & 21 estações & Planejamento \\
Linha Oeste & 14 estações & Planejamento \\
Linha Norte & 14 estações & Planejamento \\
Linha Nordeste & 8 estações & Planejamento \\
Linha Centro-Norte & 14 estações & Planejamento \\
Linha Norte (VLT) & 13 estações & Planejamento \\
Linha Sul (VLT) & 11 estações & Planejamento \\
Linha Suape (VLT) & 13 estações & Planejamento \\
\hline
\end{tabular}

Fonte: Esta pesquisa. 
No que tange a finanças, a organização não respondeu a algumas questões do questionário nem disponibilizou os dados referentes a essas perguntas. Limitou-se a informar que o custo médio é de $\mathrm{R} \$ 110,06$ por quilômetro rodado e que houve prejuízo no último exercício, porém não se sabe de quanto, pois essa informação não foi disponibilizada. Outra informação não disponibilizada foi relativa aos percentuais de gastos com despesas de pessoal, de manutenção e novos investimentos.

\subsection{Trensurb - Metrô de Porto Alegre}

Em meados de 1976, foram desenvolvidos estudos para um projeto sobre trilhos que objetivasse a redução do fluxo de veículos na BR-116 em Porto Alegre, quando foi cogitada a construção de um Metrô (Trensurb, 2013). Em 1980 foi fundada a Empresa de Trens Urbanos de Porto Alegre S.A. (Trensurb) e o início da operação de trens ocorreu em 1985 com a aquisição de 25 unidades elétricas importadas do Japão (Trensurb, 2013).

O Metrô iniciou sua operação com 15 estações e uma linha com 27 quilômetros de extensão. Atualmente possui uma única linha que liga Porto Alegre a Novo Hamburgo, constituída por 17 estações que percorrem 39 quilômetros de extensão das linhas eletrificadas, com previsão nos próximos anos de inaugurar mais três estações, somando assim mais 4,4 quilômetros em sua extensão total (Trensurb, 2013).

O sistema de Metrô de Porto Alegre transporta por dia cerca de 170 mil passageiros, dispondo de um sistema de integração com aproximadamente 600 linhas de onibus, a maioria funcionando com bilhetagem eletrônica (Trensurb, 2013). A Trensurb utiliza apenas uma tarifa unitária no valor de $\mathrm{R} \$ 1,70$, existindo descontos na compra da passagem de ônibus nos casos de integrações.

No último exercício realizado pela organização foi constatado que houve prejuízo de $\mathrm{R} \$$ 86.523.600,00. As despesas com pessoal representam 57,22\%, os serviços de terceiros, 19,85\% e o consumo de materiais, $4 \%$ do percentual de gastos. Além desses números, foram investidos no Metrô de Porto Alegre $\mathrm{R} \$$ 237.073.744,00 oriundos de recursos recebidos em 2011 por outras fontes.

O sistema de Metrô de Porto Alegre é totalmente de superfície, embora atualmente esteja em fase de estudo o rebaixamento de um trecho dentro do município de Canoas. Dispõe de 25 trens que foram adquiridos em 1985 para início da operação do sistema com uma idade de mais de 30 anos. A figura 1 demonstra o mapa de estações existentes e projetadas da Trensurb.

Recentemente foram inauguradas duas novas estações e mais três estão ainda no processo final das obras. Atualmente, encontra-se em fase de expansão o trecho relativo a Novo Hamburgo. Além disso, já foram iniciados os processos de estudo para a ampliação da linha até o município de Sapiranga. 
Figura 1

Mapa das estações existentes e projetadas para Porto Alegre

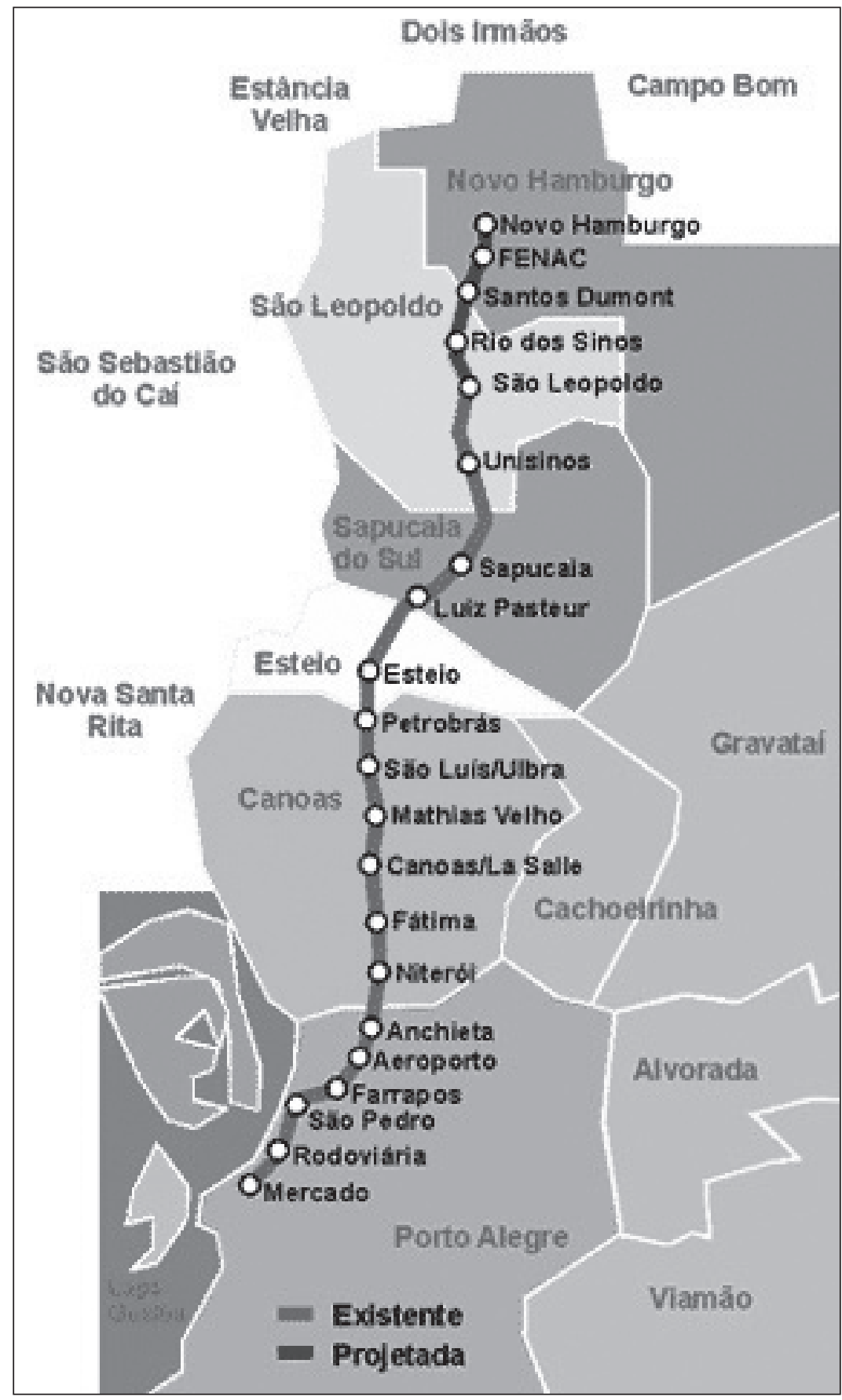

Fonte: Trensurb (2013). 


\subsection{Metrosp - Metrô de São Paulo}

A Companhia do Metropolitano de São Paulo Metrosp foi fundada em 1968 e ainda no mesmo ano foram iniciadas as obras das linhas entre a Zona Norte e a Zona Sul (Metrosp, 2013).

A Linha Norte-Sul, posteriormente intitulada Linha 1-Azul, tinha ligação direta com o bairro Jabaquara, na Zona Sul, e de Santana, na Zona Norte, passando pelo centro da cidade e englobando estações como Praça da Árvore e Santa Cruz. Esse primeiro trecho foi construído pelo método trincheira, medindo na época 2,2 quilômetros de extensão.

Em 1969 houve a primeira ampliação da Linha 1-Azul, que foram os trechos Conceição e Jabaquara, Saúde e São Judas, também subterrâneos e feitos por meio de trincheiras, e o trecho Santana e Ponte Pequena, esse feito de modo elevado. No ano de 1970, na construção do trecho Vila Mariana e Ana Rosa, houve uma desaceleração nas obras por não se contar com o apoio do governo federal. No dia 6 de setembro 1972, o primeiro protótipo de trem Metrô chega a São Paulo na estação Jabaquara, onde é realizado um teste sobre os trilhos e, após dois dias, ocorre a primeira viagem oficial, no trecho Jabaquara-Saúde (Metrosp, 2013).

No ano seguinte são finalizadas as 16 estações entre Jabaquara e Liberdade, com 31 quilômetros de vias em funcionamento e 11 quilômetros de túneis, além de iniciar-se a intercessão da Linha 1-Azul com a Linha 2-Verde (Metrosp, 2013).

Diante do avanço nas obras e do uso de tecnologias de ponta na escavação, como a utilização da máquina shield, o famoso "tatuzão", os dois primeiros trens metroviários nacionais são concluídos em janeiro de 1974. Também é inaugurado em outubro deste mesmo ano o Centro de Controle de Operações (CCO), que passou a automatizar o funcionamento dos trens que até então era feito de modo manual.

Seis anos depois são concluídas as obras de novas estações da Linha 3-Vermelha e o metrô passa a funcionar das cinco da manhã até a meia-noite (Metrosp, 2013). Em meados de 1998 inicia-se a construção da Linha 5-Lilás que liga os bairros de Capão Redondo, Capela do Socorro, Campo Limpo, Rio Pequeno, Grajaú, Piraporinha e Santo Amaro, além dos municípios de Embu, Taboão da Serra e Itapecerica da Serra (Metrosp, 2013). Quatro anos depois, em fevereiro de 2002, com 8,4 quilômetros de extensão e seis estações, é inaugurada a Linha 5-Lilás. Nesse mesmo ano o metrô assina acordo com o Banco Mundial para obter um empréstimo para a construção da Linha 4-Amarela; além disso, são fechadas parcerias público-privadas para essa construção (Metrosp, 2013).

Em maio de 2010 foi inaugurada a primeira parte do metrô que liga a Estação Luz até a Estação Butantã, que conta com seis estações e tem nove quilômetros de extensão (Metrosp, 2013).

Atualmente o Metrô conta com cinco linhas, sendo quatro de sua posse e uma independente ou público-privada. Uma síntese da extensão das linhas é demonstrada na tabela 2. 
Tabela 2

Linhas do Metrô de São Paulo

\begin{tabular}{|lcc|}
\hline \multicolumn{1}{|c|}{ Linha } & Extensão & Número de Estações \\
\hline Azul (Linha 1) & $20,2 \mathrm{~km}$ & 23 \\
Verde (Linha 2) & $14,7 \mathrm{~km}$ & 14 \\
Vermelha (Linha 3) & $22,0 \mathrm{~km}$ & 18 \\
Amarela (Linha 4) & $9,0 \mathrm{~km}$ & 6 \\
Lilás (Linha 5) & $8,8 \mathrm{~km}$ & 6 \\
Total & $74,7 \mathrm{~km}$ & 67 \\
\hline
\end{tabular}

Fonte: Esta pesquisa.

O Metrô de São Paulo transporta cerca de 3,75 milhões de passageiros por dia útil, o que corresponde a uma média de 57,4 mil passageiros transportados por quilômetro de linha. Estes dados não contemplam os passageiros da Linha 4-Amarela, pois esse ramal é administrado pelo consórcio Via Quatro, que não fez parte da pesquisa em função de o Metrosp não ter acesso a esta informação, segundo o entrevistado.

Atualmente são integradas cerca de 720 linhas de ônibus de ponto final dos terminais urbanos ou nos arredores das estações do metrô. Destas linhas, 73\% operam dentro do município de São Paulo e são administradas pela SPTrans e 27\% fazem ligação com os demais municípios que formam a Região Metropolitana de São Paulo, sendo esses administrados pela Emtu.

É possível a integração ônibus/metrô através do bilhete. No ano de 2012, aproximadamente $29 \%$ do total de entradas pelas linhas de bloqueio utilizaram-se dessa integração.

O sistema de Metrô de São Paulo é dividido em dois tipos diferentes de bilhetes: o único e o magnético, cada um com diversos tipos de tarifas. O bilhete único dispõe de 11 tarifas diferentes para perfis de embarque, conforme descrito na tabela 3.

Tabela 3

\section{Base tarifária do Metrô de São Paulo}

\begin{tabular}{|ll|}
\hline \multicolumn{1}{|c|}{ Linha } & Extensão \\
\hline Unitário Metrô & $\mathrm{R} \$ 3,00$ \\
Madrugador & $\mathrm{R} \$ 2,50$ \\
Da Hora & $\mathrm{R} \$ 2,50$ \\
Estudante/Professor & $\mathrm{R} \$ 1,50$ \\
Fidelidade 8 Viagens & $\mathrm{R} \$ 2,79$ \\
Fidelidade 20 Viagens & $\mathrm{R} \$ 2,69$ \\
Fidelidade 50 Viagens & $\mathrm{R} \$ 2,55$ \\
Lazer & $\mathrm{R} \$ 2,50$ \\
Integração & $\mathrm{R} \$ 4,65$ \\
Integração Madrugador & $\mathrm{R} \$ 4,21$ \\
Integração Da Hora & $\mathrm{R} \$ 4,21$ \\
\hline
\end{tabular}

Fonte: Esta pesquisa. 
O bilhete magnético dispõe de apenas três tipos de tarifas: Unitário Metrô, que custa um valor de R \$ 3,00; Integração Trólebus, cujo valor é de R \$ 5,70; e o bilhete de Integração Tamanduateí, que custa $\mathrm{R} \$ 5,10$, ambos emitidos pela Emtu.

No último exercício, referente ao ano de 2011, houve prejuízo de R\$24.569.000,00. O percentual de gastos com despesa de pessoal em relação ao gasto total é de 63,45\% e o percentual de gastos com manutenção e novos investimentos em relação também ao gasto total é de 28,34\%. Os dados relacionados ao valor do custo médio por quilômetro rodado não foram disponibilizados pelo entrevistado.

O Metrô de São Paulo dispõe tanto de linhas de superfície como subterrâneas, sendo um metrô com características mistas. Não foi disponibilizada a quantidade total de trens usados em sua frota, somente o modelo, ano de fabricação e o tempo de uso, conforme a tabela 4.

$$
\text { Tabela } 4
$$

Frota do Metrô de São Paulo por ano de fabricação

\begin{tabular}{|cc|}
\hline Frota & Fabricação \\
\hline 198 & 1974 \\
108 & 1979 \\
COB & 1986 \\
MAF & 1986 \\
A66 & 2000 \\
A48 & 2002 \\
A96 & 2009 \\
CAF & 2010 \\
ASI & 2012 \\
BTT & 2012 \\
MTT & 2012 \\
AIE & 2012 \\
\hline
\end{tabular}

Fonte: Esta pesquisa.

Atualmente existem diversas iniciativas de expansão tanto em atividade quanto em projeto, conforme demostrado no quadro 2.

Essas três citadas por último na Tabela têm como objetivo do governo de São Paulo a Parceria Público-Privada (PPP), que deve contemplar a execução dos projetos, as obras, a compra de trens e de equipamentos, além da operação e manutenção da linha pelo prazo da concessão. 
Quadro 2

Expansão do Metrô de São Paulo

\begin{tabular}{|lcl|}
\hline \multicolumn{1}{|c}{ Linha } & Estações/Extensão & Fase \\
\hline Amarela (Linha 4) & 5 estações $/ 12,8 \mathrm{~km}$ & Obras \\
Lilás (Linha 5) & 11 estações $/ 11,4 \mathrm{~km}$ & Obras \\
Prata (Linha 15) & 17 estações $/ 24,3 \mathrm{~km}$ & Obras \\
Ouro (Linha 17) & 18 estações $/ 17,9 \mathrm{~km}$ & Obras \\
Verde (Linha 2) & 15 estações $/ 17 \mathrm{~km}$ & Projeto \\
Amarela (Linha 4) & 2 estações $/ 3,1 \mathrm{~km}$ & Projeto \\
Prata (Linha 15) & 1 estação/1,5 km & Projeto \\
Laranja (Linha 6) & 15 estações $/ 13,5 \mathrm{~km}$ & Em licitação \\
Bronze (Linha 18) & 12 estações $/ 14,3 \mathrm{~km}$ & Em estudo \\
Rosa (Linha 20) & 14 estações $/ 12,3 \mathrm{~km}$ & Em estudo \\
\hline
\end{tabular}

Fonte: Esta pesquisa.

\subsection{METRODF - Metrô de Brasília}

A Companhia do Metropolitano do Distrito Federal (METRODF) foi constituída em 1993, pouco depois do início das obras das linhas do Metrô de Brasília. Após uma série de paralisações e funcionamentos em caráter experimental, a operação iniciou formalmente em 2001 com a inauguração do trecho que liga Samambaia, Taguatinga, Águas Claras e Guará (Metrô-DF, 2013).

Em 2006, iniciou-se a operação de ligação entre os trechos de Taguatinga até Ceilândia Sul, passando pela estação Centro Metropolitano (Metrô-DF, 2013). Em 2007, as obras foram retomadas para levar o Metrô-DF até a parte norte de Ceilândia e houve também nesse ano uma importante mudança operacional no horário das 16 estações, que passaram a funcionar em um horário ampliado (Metrô-DF, 2013).

Em 2008 a malha foi expandida com a inauguração de três estações e um terminal, com a conclusão do trecho de Ceilândia, complementada a estação 108 Sul, totalizando 42 quilômetros de linhas (Metrô-DF, 2013).

Atualmente o Metrô-DF conta com 24 estações em funcionamento que são totalmente eletrificadas e percorrem 42 quilômetros de extensão das linhas eletrificadas. O sistema do Metrô de Brasília contabiliza o transporte de aproximadamente 125 mil passageiros e dispõe de integração com 38 linhas, sendo sete delas de ônibus e 31 micro-ônibus por meio de bilhetes únicos ou de cartões eletrônicos. Não foram disponibilizadas pelo entrevistado as informações referentes à média de passageiros transportados por quilômetro rodado. 
O METRODF utiliza-se de apenas um tipo de bilhete que é unitário e tem suas tarifas variantes com o fim de semana: de segunda-feira até sexta-feira o custo do bilhete é de $\mathrm{R} \$$ 3,00; aos sábados, domingos e feriados o bilhete passa a custar R $\$ 2,00$.

Quanto às finanças, a organização não respondeu a algumas questões do questionário nem disponibilizou os dados referentes a esse tópico. Foi informado que o custo médio foi de aproximadamente $\mathrm{R} \$ 79,92$ por quilômetro rodado em 2012.

Não foi informado se, no último exercício, a organização obteve lucro ou prejuízo, nem de quanto foi, nem os gastos de manutenção e de novos investimentos. A única informação financeira obtida além dos custos tarifários dos bilhetes foram as despesas de pessoal no mês de janeiro de 2013, que resultaram em $\mathrm{R} \$ 6.682 .833,64$.

O sistema de Metrô oferecido pelo METRODF é misto, parte é em superfície e parte é subterrânea. O Metrô de Brasília conta também com 32 trens, 20 são da série 1000, tendo 16 fabricados no período entre os anos de 1993 e 1994, três fabricados em 1998 e um fabricado em 1999, e 12 da série 2000, que foram fabricados entre os anos de 2009 e 2010.

Atualmente, o METRODF tem um projeto de expansão que consiste na ampliação da rede metroviária de sua única linha existente, construindo mais cinco estações com aproximadamente mais 6,7 quilômetros de extensão divididos em três trechos. O primeiro trecho é o que vem logo após a Estação Samambaia que terá mais duas estações e aumentará essa parte do ramal em mais 3,8 quilômetros de extensão.

O segundo trecho é o que vem após a Estação Ceilândia, que também somará mais duas estações à malha e que irão medir 2.064 metros de extensão. E o terceiro trecho é o que vai no sentido Asa Norte, que contará com uma estação subterrânea que somará mais 820 metros ao norte da cidade. Além dessa estação, está ainda em planejamento a construção de mais sete estações neste sentido do trecho Asa Norte.

A figura 2 ilustra as partes construídas que estão em operação, as partes que estão em expansão e o que ainda está em fase de planejamento.

\subsection{METROBH - Metrô de Belo Horizonte}

Ao término dos anos 1970, o órgão de planejamento do Ministério dos Transportes, a extinta Empresa Brasileira de Planejamento de Transportes (Geipot), foi encarregada de desenvolver um transporte de passageiros sobre linhas férreas de forma viável para a Região Metropolitana de Belo Horizonte, com o intuito de diminuir o fluxo de veículos nas ruas (METROBH, 2013).

O projeto de início visava uma ligação entre Betim, na zona oeste, e São Gabriel, zona norte, com uma ramificação para Barreiro, a sudoeste, totalizando assim 60 quilômetros de plataforma ferroviária em faixa totalmente vedada, transposições inferiores e superiores para veículos e pedestres, com previsão para 22 estações, 25 unidades de trens elétricos e terminais para integração (METROBH, 2013). 
Figura 2

Mapa das estações em operação e projeto de expansão

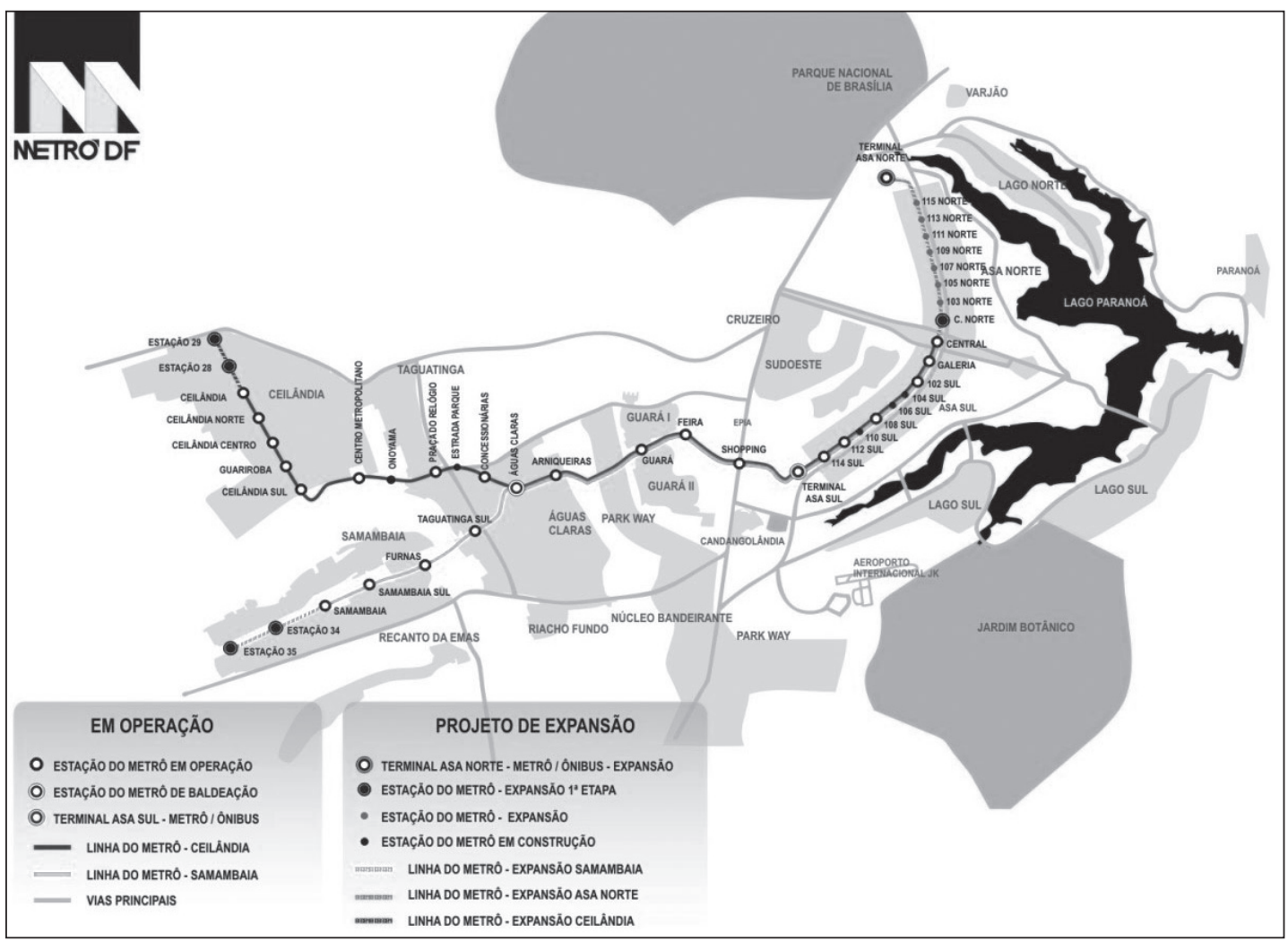

Fonte: METRÔ-DF (2013).

O Metrô em Belo Horizonte teve seu início em 1981, com a construção do trecho que liga Eldorado a São Gabriel, com 26,5 quilômetros, e a ramificação que vai de Calafate até Barreiro, com 10,5 quilômetros de extensão (METROBH, 2013).

Os recursos para a construção do Metrô surgiam por intermédio de uma parceria com o governo federal (que por sua vez cuidaria das obras, superestruturas, montagem dos trens, desapropriações e infraestrutura), com o Programa de Mobilização Energética e com o governo francês, que financiaria os equipamentos necessários para os sistemas de telecomunicação e sinalização e também parte do material rodante (METROBH, 2013). Apesar de ter recebido os recursos dos franceses no tempo certo, o governo federal parou as obras por conta do encerramento do Programa de Mobilização Energética e por não ter em vista novas fontes de investimentos formalizadas, atrasando o cronograma em um ano (METROBH, 2013).

Algumas obras pararam pela metade, dificultando assim o acesso dos pedestres com as integrações. Em 1991, mediante o apoio do Congresso Nacional, foram obtidos recursos do Orçamento da União para retomar as obras do Metrô de Belo Horizonte e a montagem dos 20 trens restantes que estavam "congelados” desde 1986 (METROBH, 2013). 
O METROBH foi aberto para funcionamento no dia 1ํ de agosto de 1986, porém com um funcionamento parcial, no qual só percorria seis estações com 10,8 quilômetros de extensão ligando Eldorado até a Lagoinha e com apenas três trens operando. No ano seguinte foram incorporados mais dois trens juntamente com o trecho da Estação Central. Depois disso, só a partir de 1994 houve a incorporação de mais trens, porém a frota de 25 trens só foi completada em dezembro de 2001 (METROBH, 2013).

Na figura 3, o mapa ilustrativo do percurso percorrido pelo Metrô de Belo Horizonte.

\section{Figura 3}

Mapa das estações em operação do Metrô de Belo Horizonte

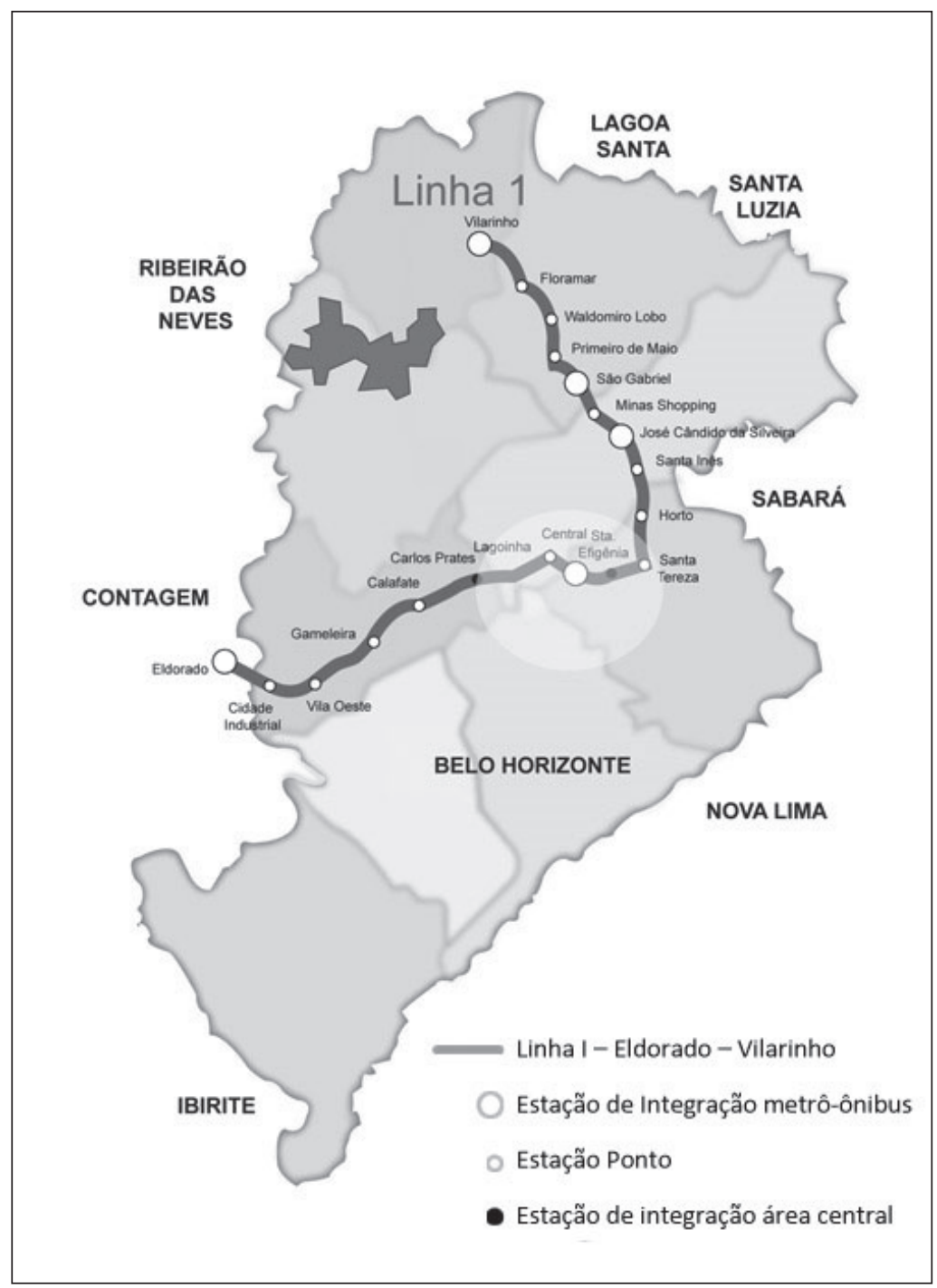

Fonte: METROBH (2013). 
Embora o mapa apresente 19 estações, atualmente o METROBH se utiliza de uma forma mista e conta com apenas uma linha com 14 estações e com 28,1 quilômetros de extensão.

As estações em operação vão da Estação Eldorado até a Estação São Gabriel. A frota é composta por 25 unidades de trens elétricos. As Estações Vila Oeste, José Cândido, Minas Shopping, Primeiro de Maio, Waldomiro Lobo, Floramar e Vilarinho ainda estão em fase de estudos (Crea-MG, 2013).

As questões referentes ao número de extensão das linhas, quantidade de pessoas transportadas por dia, funcionamento e quantidade de integrações com ônibus ou com outro tipo qualquer de modal, tarifas relativas ao preço dos bilhetes, custo médio por quilômetro rodado, valor do lucro ou prejuízo no fechamento do exercício anterior, percentual de gastos com despesas de pessoal, manutenção e novos investimentos, tempo de fabricação e uso de cada trem e vagão e possibilidades de expansão ou construção de novas linhas não foram respondidas pelo órgão que rege o Metrô de Belo Horizonte.

Apesar dos contatos pela internet e por meio de telefone, não houve um retorno com as respostas do questionário nem nenhuma outra resposta. Todas as informações referentes ao METROBH citadas anteriormente foram extraídas de sites institucionais e informações disponíveis em atas de conferência.

\subsection{Metrorio - Metrô do Rio de Janeiro}

O metrô carioca foi inaugurado em 1979, contando inicialmente com cinco estações e percorrendo 4,3 quilômetros, sendo esta a Linha 1 (Metrorio, 2013). De início, seu funcionamento contava com quatro composições com quatro vagões cada. Para atender à demanda crescente esse número foi rapidamente ampliado para seis composições, juntamente com a inauguração de mais duas estações. No decorrer dos anos o Metrô do Rio de Janeiro foi ampliado com a adição de novas estações, conforme descrito na tabela 5.

Em 1997, o Consórcio Opportrans adquiriu o direito de, por 20 anos, explorar o serviço metroviário do Metrorio (do qual possui a concessão do controle, administração e operação do metrô carioca), ficando ao encargo da organização Rio Trilhos as expansões e aquisições de novos trens (Metrorio, 2013).

O Metrorio passou a fazer parte, em dezembro de 2009, do Grupo de Investimentos e Participações em Infraestrutura S.A. (Invepar), juntando-se a Concessionária Auto Raposo Tavares (Cart) de São Paulo, a Linha Amarela S.A. do Rio de Janeiro e a Concessionária Litoral Norte (CLN) da Bahia (Metrorio, 2013).

Atualmente o Metrorio utiliza a forma de metrô misto (partes subterrâneas e partes de superfície), contando com duas linhas que totalizam 35 estações, sendo 10 dessas estações compartilhadas entre ambas as linhas que percorrem 46,2 quilômetros de extensão. 
Tabela 5

Histórico de expansão do Metrô do Rio de Janeiro

\begin{tabular}{|ccc|}
\hline Linha & Estações Inauguradas & Ano \\
\hline Linha 1 & 5 & 1979 \\
Linha 1 & 2 & 1980 \\
Linha 1 & 5 & 1981 \\
Linha 2 & 2 & 1981 \\
Linha 1 & 3 & 1982 \\
Linha 2 & 4 & 1983 \\
Linha 2 & 1 & 1988 \\
Linha 1 & 3 & 1991 e 1996 \\
Linha 1 & 1 & 1998 \\
Linha 2 & 5 & 1998 \\
Linha 1 & 1 & 2003 \\
Linha 1 & 3 & 2007 \\
Linha 2 & 1 & 2007 \\
Linha 1 & 1 & 2009 \\
\hline
\end{tabular}

Fonte: Metrorio (2013).

A Linha 1 é formada por 19 estações, que percorrem 16 quilômetros de extensão, e a Linha 2 é formada por 26 estações, que percorrem 30,2 quilômetros de extensão (Metrorio, 2013).

A figura 4 traz o mapa das estações já existentes do Metrô do Rio de Janeiro.

Não foram recebidas respostas na entrevista sobre extensão das linhas (porém essas foram obtidas pelo site do metrô), quantidade de pessoas transportadas por dia, funcionamento e quantidade de integrações com ônibus ou com outro tipo qualquer de modal, tarifas relativas ao preço dos bilhetes, custo médio por quilômetro rodado, valor do lucro ou prejuízo no fechamento do exercício anterior, percentual de gastos com despesas de pessoal, manutenção e novos investimentos, tempo de fabricação e de uso de cada trem e vagão e possibilidades de expansão ou construção de novas linhas.

A instituição também não se mostrou interessada no assunto, nem permitiu que um contato fosse estabelecido. A linha histórica e algumas das características do Metrorio existentes neste trabalho foram obtidas no site da instituição. 
Figura 4

Mapa das estações em operação do Metrô Rio

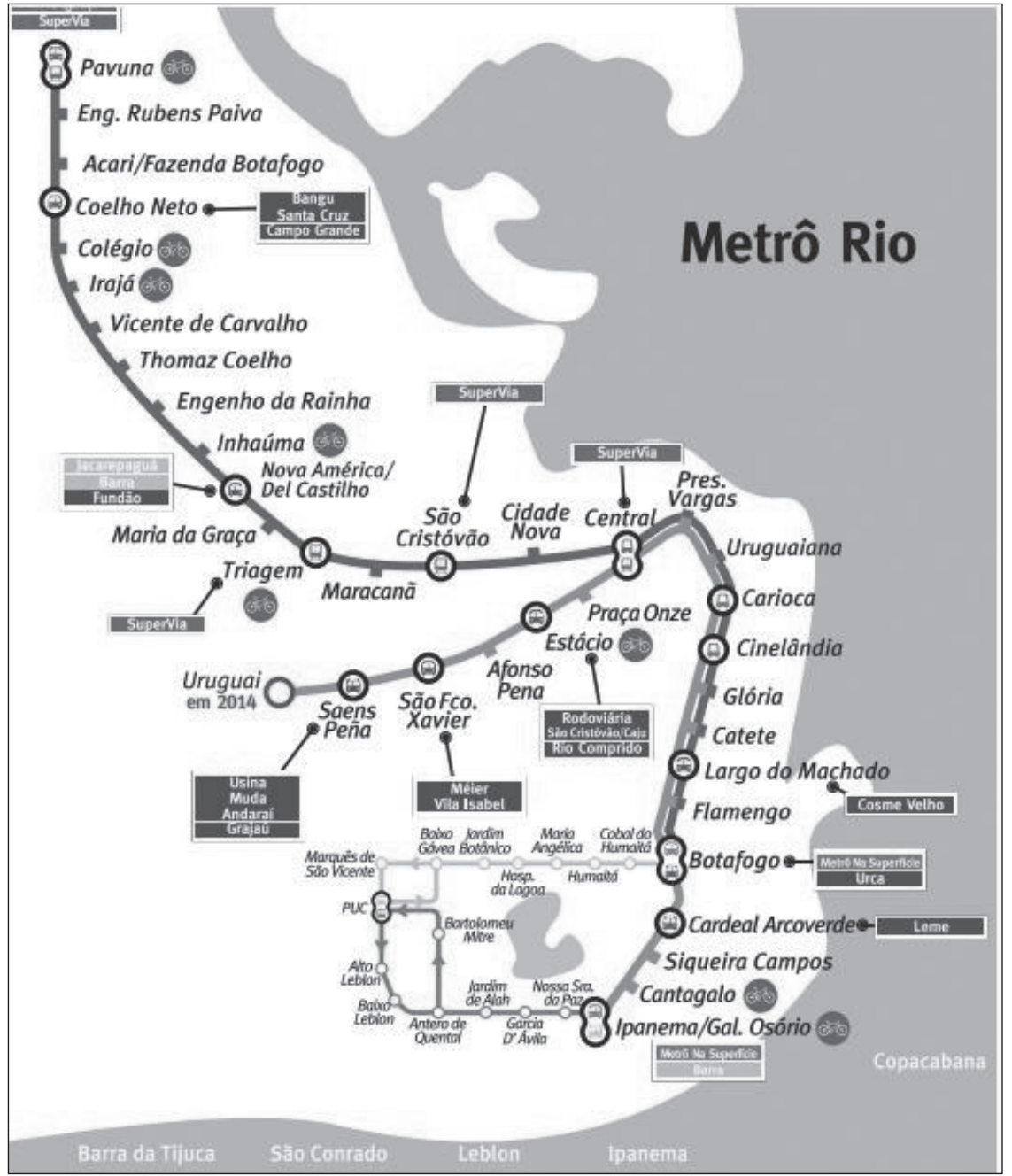

Fonte: Metrorio (2013).

\subsection{CMTP - Metrô de Teresina}

O Metrô de Teresina, administrado pela Companhia Metropolitana de Transportes Públicos (CMTP), foi construído para ser o principal meio de transporte público urbano da capital do Piauí (CMTP, 2013).

Em sua primeira etapa, a malha ferroviária consistia em reaproveitar um trecho de 8,5 quilômetros de trilhos da REFFSA que ligava a parte leste da cidade à parte oeste (CMTP, 
2013). Além desse reaproveitamento, a primeira etapa também consiste na construção dos ramais de Itararé, que inicia e termina na linha RFFSA e tem 6,9 quilômetros de extensão, e de outro ramal, que tem pouco mais de um quilômetro de extensão e está ligando a linha de Rede na Matinha até a praça Marechal Deodoro (Bandeira), através da avenida Maranhão (CMTP, 2013).

Ao logo desses dois ramais foram previstas 15 estações posicionadas estrategicamente nos pontos de maior demanda, das quais três estariam compondo o sistema de integração com os ônibus (CMTP, 2013).

Para melhorar as passagens de nível existentes no curso da ferrovia, foi elaborado um projeto contemplando a construção de viadutos e o rebaixamento do greide ferroviário em 3,3 quilômetros da área central da cidade (CMTP, 2013).

As unidades escolhidas para o transporte de passageiros foram os Trens Leves a Diesel (TLD), porém, pela falta de verba, os Ganz Mávac, fabricados na Hungria, foram cedidos e adaptados pela RFFSA (CMTP, 2013).

Esses trens foram adquiridos em 1973 e encontravam-se desativados desde 1987. Por isso, algumas adaptações básicas precisaram ser realizadas, como substituição das janelas e mudança do piso com a colocação de acentos na vertical e na horizontal ao nível do piso (CMTP, 2013). Além disso, as composições passaram a contar com um novo sistema de iluminação alimentado por baterias mais duradouras que eram ligadas a um novo gerador auxiliar (CMTP, 2013).

O Metrô de Teresina é totalmente de superfície e foi inaugurado em novembro de 1990, porém só contava com parte dos componentes para seu funcionamento total. O ramal Bandeira, juntamente com o ramal Itararé, só conta com oito estações e com quatro quilômetros de extensão de vias, levando em consideração as 15 estações e seus sete quilômetros de extensão projetados. Além disso, a estrutura das estações ainda é muito precária e os trechos são de construções antigas que não foram reformadas quando obtidas pela RFFSA (CMTP, 2013).

Não foi conseguido contato com o Metrô de Teresina nem através da internet nem por telefone, pois no seu site não há nenhum meio de contato com a administração do Metrô. Assim, não houve possibilidade de enviar o questionário para essa operadora. Infelizmente, alguns dos dados disponibilizados no site não são atualizados desde 2002, o que impediu seu uso na presente pesquisa.

\section{Análise global dos resultados}

Foram incluídos na pesquisa os sete metrôs brasileiros. Apenas quatro responderam os questionários. As demais análises utilizaram fontes bibliográficas. Despido do fato de possuir uma grande necessidade de ênfase no transporte urbano por trilhos, o Brasil conta apenas com sete operações de metrô em funcionamento. 
Tabela 6

\section{Comparativo das características básicas dos metrôs brasileiros}

\begin{tabular}{|l|c|c|c|c|}
\hline \multicolumn{1}{|c|}{ Cidade } & Número de Linhas & Estações & $\begin{array}{c}\text { Extensão } \\
(\mathrm{em} \mathrm{km})\end{array}$ & $\begin{array}{c}\text { Integração } \\
\text { com Ônibus }\end{array}$ \\
\hline São Paulo & 5 & 67 & 74,7 & 720 \\
\hline Recife & 3 & 36 & 71 & 111 \\
\hline Rio de Janeiro & 2 & 35 & 46,2 & Não informado \\
\hline Brasília & 1 & 24 & 42 & 38 \\
\hline Porto Alegre & 1 & 17 & 39 & 600 \\
\hline Belo Horizonte & 1 & 14 & 28,1 & Não informado \\
\hline Teresina & 1 & 8 & 4 & Não informado \\
\hline
\end{tabular}

Fonte: Esta pesquisa, METROBH (2013), Metrorio (2013), CMTP (2013), Metrosp (2013), Metrô-DF (2013) e Trensurb (2013).

O metrô com o maior número de linhas, estações e extensão é o de São Paulo, que conta com cinco linhas, 67 estações e tem uma extensão de 74,7 quilômetros. Em seguida está o Metrorec (Recife), com duas linhas eletrificadas e uma a diesel, somando 36 estações com uma extensão de 71 quilômetros. O Metrorio (Rio de Janeiro) ocupa a terceira colocação com suas duas linhas, 35 estações e 46,2 quilômetros de extensão. O Metrô de Brasília tem apenas uma linha com 24 estações e 42 quilômetros de extensão. O Metrô de Porto Alegre tem apenas uma linha, 17 estações e uma extensão de 39 quilômetros. O METROBH também tem apenas uma linha e conta com 14 estações que percorrem 28,1 quilômetros de extensão. Por último, mas não menos importante, está o Metrô de Teresina com uma linha de oito estações que percorrem quatro quilômetros de extensão.

Com relação às informações postas nas entrevistas foi possível elaborar um quadro de comparação entre as operadoras de metrô, que é demostrado na tabela 7.

Tabela 7

Dados comparativos das entrevistas

\begin{tabular}{|l|c|c|c|c|}
\hline & Recife & Porto Alegre & São Paulo & Brasília \\
\hline Média de passageiro/km & 42,4 & 17,64 & 57,4 mil & Não informado \\
\hline $\begin{array}{l}\text { Média de transportados/ } \\
\text { dia }\end{array}$ & 280 mil & 171 mil & 3,75 milhões & 125 mil \\
\hline Média tarifária & $\mathrm{R} \$ 2,73$ & $\mathrm{R} \$ 1,70$ & $\mathrm{R} \$ 3,54$ & $\mathrm{R} \$ 2,50$ \\
\hline Custo médio/km rodado & $\mathrm{R} \$ 110,06$ & $\mathrm{R} \$ 6,37$ & Não Informado & $\mathrm{R} \$ 79,92$ \\
\hline Lucro ou prejuízo & $\begin{array}{c}\text { Prejuízo (valor não } \\
\text { informado) }\end{array}$ & $\begin{array}{c}\text { Prejuízo de } \mathrm{R} \$ \\
86.523 .600,00\end{array}$ & $\begin{array}{c}\text { Prejuízo de } \mathrm{R} \$ \\
24.569 .000,00\end{array}$ & Não informado \\
\hline Despesas de pessoal & Não informado & $57,22 \%$ & $63,45 \%$ & $\mathrm{R} \$ 6.682 .833,64$ \\
\hline Despesas de manutenção & Não informado & $23,85 \%$ & $28,34 \%$ & Não informado \\
\hline Novos investimentos & Não informado & $\mathrm{R} \$ 237.073 .744,00$ & Não informado & Não informado \\
\hline
\end{tabular}

Fonte: Esta pesquisa. 
A média de passageiros por quilômetro no Metrô de São Paulo é de 57,4 mil, enquanto em Recife é de 42,4 e em Porto Alegre é de 17,64.

A média de passageiros transportados por dia no Metrô de São Paulo é de 3,75 milhões, no Metrô do Recife é de aproximadamente 280 mil, no Metrô de Porto Alegre é de mais de 170 mil e no Metrô de Brasília é de cerca de 125 mil pessoas por dia.

Entre os valores cobrados referentes às tarifas de bilhetes, o Metrô de São Paulo tem a maior variedade de taxas e a maior média de custo de bilhete, que é de $\mathrm{R} \$ 3,54$; logo em seguida vem o Metrô do Recife, com a média de taxas cobradas por bilhete de $\mathrm{R} \$ 2,73$; o valor médio dos bilhetes em Brasília chega próximo ao valor referente do metrô anterior e é de $\mathrm{R} \$ 2,50$; por fim e com a taxa cobrada mais barata, está o Metrô de Porto Alegre, com o valor de R\$1,70.

O maior custo médio por quilômetro rodado, de acordo com a pesquisa realizada, pertence à companhia de trilhos estabelecida no Recife, que é o valor de $\mathrm{R} \$ 110,06$, seguido de Brasília com seus $\mathrm{R} \$ 79,92$ e Porto Alegre com $\mathrm{R} \$$ 6,37, respectivamente. Os dados referentes ao custo médio por quilômetro rodado dos outros metrôs não foram informados nem encontrados.

De acordo com os dados recolhidos, o Metrô de Recife fechou o exercício anterior com prejuízo, mas não foi disponibilizado e nem encontrado o valor específico. Os metrôs de São Paulo e Porto Alegre também fecharam em prejuízo e foram os únicos que informaram o

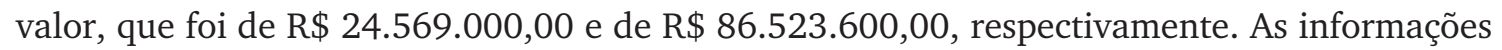
referentes ao lucro ou prejuízo do exercício anterior dos outros metrôs não foram citadas por não serem obtidas através de nenhum meio.

O Metrô de porto Alegre teve 57,22\% de despesas com pessoal, 23,85\% com despesas de manutenção e $\mathrm{R} \$ 237.073 .744,00$ para novos investimentos. O Metrô de São Paulo informou que tiveram em seu último exercício 63,45\% de despesas com pessoal e 28,34\% em despesas com manutenção e novos investimentos em relação ao gasto total. O Metrô de Brasília informou apenas o total de despesas de pessoal do mês de janeiro de 2013, que foi de R\$ 6.682.833,64. Os outros metrôs não informaram nenhum dos dados relacionados neste parágrafo.

Os metrôs de Recife, Porto Alegre e Teresina são totalmente de superfície e os metrôs de Brasília, São Paulo, Belo Horizonte e Rio de Janeiro têm a forma de utilização mista, com alguns trechos subterrâneos e outros de superfície.

\section{Considerações finais}

O uso de sistemas de metrô tem sido aplicado como uma importante ferramenta para promoção da mobilidade urbana em diversas metrópoles mundiais. Uma composição de metrô convencional equivale a 31 ônibus ou a 1.200 automóveis (Metrorio, 2013). Por ser uma ferramenta essencial para o transporte de massa, sua aplicação em regiões de grandes congestionamentos pode promover visíveis melhoras no trânsito e no fluxo de pessoas. 
Apesar das vantagens evidentes dos trens metropolitanos, pode-se observar que o Brasil ainda está pouco estruturado na questão. O ritmo de investimento para implantação ou ampliação destes serviços não é suficiente para manter os níveis de serviço desejáveis. À exceção do metrô de São Paulo, todas as demais regiões apresentam baixas taxas de expansão.

Um segundo problema observado nos metrôs brasileiros está no planejamento de rotas. A maioria dos metrôs opera com linhas que não foram projetadas de acordo com a demanda. Na verdade, a iniciativa de construção da maioria dos metrôs brasileiros veio da disponibilidade de linhas herdadas da extinta RFFSA. As linhas da RFFSA, que foram projetadas há décadas, tinham o propósito inicial de movimentação de cargas e transportes inter-regionais de passageiros e não para uso urbano.

Exceto Rio de Janeiro e São Paulo, as demais expansões de metrô se limitaram a reativação ou reciclagem de linhas antigas, fazendo com que as estações de metrô se localizem em regiões de difícil acesso. Para equalizar este problema, os serviços de metrô, como o de Recife, possuem diversas integrações com ônibus e BRTs. Apesar de ser uma prática comum, isto reduz e limita as vantagens inerentes dos sistemas de metrô (como velocidade e capacidade), gerando gargalos nos terminais integrados.

Talvez as principais limitações encontradas na realização deste estudo foram o acesso às informações e a disposição de algumas concessionárias em atender o pesquisador. A criação de canais específicos de contato com a população e a comunidade acadêmica seria recomendável.

A pesquisa utilizou os mesmos canais que um cidadão regular traçaria para manter contato com as concessionárias. A julgar pela dificuldade de contato que os pesquisadores encontraram, pode-se observar que existem sérios entraves na comunicação com o usuário, distanciando assim a relação com o cidadão.

Como sugestão para trabalhos futuros recomenda-se o aprofundamento em questões sobre qualidade do serviço prestado e satisfação do usuário e também a realização de pesquisas junto às esferas de governo com vistas a analisar a possibilidade de implantação de serviços de metrô em outras cidades ainda não atendidas e à aplicação da metodologia multicritério para classificação da malha ferroviária usando o ElectrE TRI-NG (Sobral e Costa, 2012).

\section{Referências}

ANTT. TAV Brasil: Trem de Alta Velocidade. Agência Nacional de Transportes Terrestres, 2013. Disponível em: <www.antt.gov.br/index.php/content/view/5448.html>. Acesso em: 4 abr. 2013.

BARMAN, Roderick J. Business and government in Imperial Brazil: the experience of Viscount Maua. Journal of Latin American Studies, Londres, v. 61, n. 2, p. 239-264, 1981.

BLADEN, M. L. Construction of railways in Canada. Part II: From 1885 to 1931. Contributions to Canadian Economics, v. 7, n. 1, p. 61-107, 1934. 
BOLLINGER, Christopher R.; IHLANFELDT, Keith R. The impact of Rapid Rail Transit on economic development: the case of Atlanta's MARTA. Journal of Urban Economics, v. 42, n. 2, p. 179-204, 1997.

CAMAGNI, Roberto; GIBELLI, Maria C.; RIGAMONTI, Paolo. Urban mobility and urban form: the social and environmental costs of different patterns of urban expansion. Ecological Economics, v. 40, n. 2, p. 199-216, 2002.

CBTU/METROREC. Metrorec. CBTU, 2013. Disponível em: <www.cbtu.gov.br/operadoras/sites/ menuprincrec.htm>. Acesso em: 6 abr. 2013.

CMTP. Sistema Público de Transporte de Passageiros de Teresina. Companhia Metropolitana de Transportes Públicos, 2013. Disponível em: <www.florianonet.com.br/metro-pi/introducao.htm>. Acesso em: 7 abr. 2013.

CREA-MG. Operação e expansão do Metrô de Belo Horizonte. In: SEMINÁRIO INTRNACIONAL DE MOBILIDADE URBANA, 2013, Belo Horizonte. Disponível em: <www.crea-mg.org.br/mobilidade/ palestras>. Acesso em: 7 abr. 2013.

DALBEM, Maria C. et al. Avaliação econômica de projetos de transporte: melhores práticas e recomendações para o Brasil. Rev. Adm. Pública, v. 44, n. 1, p. 87-117, jan./fev. 2010.

DNIT. A invenção da locomotiva. Dnit-Ferroviário, 2013. Disponível em: <www1.dnit.gov.br/ferrovias/historico.asp>. Acesso em: 4 mar. 2013.

HAQUE, Mazharul M.; CHIN, Hoong C.; DEBNATH, Ashim K. Sustainable, safe, smart-three key elements of Singapore's evolving transport policies. Transport Policy, v. 27, n. 1, p. 20-31, 2013.

KIM, Sungyop; ULFARSSON, Gudmundur F. Commitment to light rail transit patronage: case study for St. Louis Metrolink. Journal of Urban Planning and Development, v. 138, n. 3, p. 227-234, 2012.

KUHNIMHOF, Tobias et al. Travel trends among young adults in Germany: increasing multimodality and declining car use for men. Journal of Transport Geography, v. 24, n. 1, p. 443-450, 2012.

MAGLEV COBRA. Maglev, 2013. Disponível em: <www.maglevcobra.com.br/>. Acesso em: 4 abr. 2013.

MEJÍA-DUGAND, Santiago et al. Lessons from the spread of Bus Rapid Transit in Latin America. Journal of Cleaner Production, v. 50, p. 82-90, jul. 2013.

METROBH. Histórias antecedentes. METROBH, 2013. Disponível em: <www.metrobh.gov.br/cbtu/ final/empresa/a_cbtu/acbtu.htm>. Acesso em: 7 mar. 2013.

METRÔ-DF. Memória. Companhia do Metropolitano do Distrito Federal, 2013. Disponível em: <www.metro.df.gov.br/sobre-o-metro/memoria.html>. Acesso em: 7 abr. 2013.

METRORIO. O metrô carioca. Concessão Metroviária do Rio de Janeiro S.A., 2013. Disponível em: <www.metrorio.com.br/aEmpresa.htm\#sobre_o_metro>. Acesso em: 7 abr. 2013.

METROSP. Companhia do Metropolitano de São Paulo. Empresa, 2013. Disponível em: <www. metro.sp.gov.br/metro/index.aspx>. Acesso em: 7 abr. 2013. 
MILLARD-BALL, Adam; SCHIPPE, Lee. Are we reaching peak travel? Trends in passenger transport in eight. Transport Reviews, v. 21, n. 3, p. 357-378, 2010.

NES, Rob van; BOVY, Piet H. L. Multimodal traveling and its impact on urban transit network design. Journal of Advanced Transportation, v. 38, n. 3, p. 225-241, 2004.

NIEDZIELSKI, Michael A.; MALECKI, Edward J. Making tracks: rail networks in world cities. Annals of the Association of American Geographers, v. 102, n. 6, p. 1409-1431, ago. 2012.

OHTA, Hiroyuki et al. Analysis of the acceptance of carsharing and eco-cars in Japan. International Journal of Sustainable Transportation, v. 7, n. 6, p. 449-467, 2013.

RFFSA. Histórico da RFFSA. Rede Ferroviária Federal Sociedade Anônima — RFFSA, 2013. Disponível em: <www.rffsa.gov.br/> . Acesso em: 4 abr. 2013.

ROSA FILHO, Duarte D. S. Poder simbólico no reajuste tarifário do transporte metropolitano de passageiros de Porto Alegre na crise de 2004. Rev. Adm. Pública, v. 45, n. 3, p. 643-668, maio/jun. 2011.

SETTI, João B. Ferrovias do Brasil: um século e meio de inovação. Rio de Janeiro: Memória do Trem, 2008.

SILVEIRA, Márcio R.; COCCO, Rodrigo G. Transporte público, mobilidade e planejamento urbano: contradições essenciais. Estudos Avançados, São Paulo, v. 27, n. 79, p. 41-53, 2013.

SOBRAL, Marcos F. F.; COSTA, Ana P. C. S. Negotiation model for group decision with Electre TRI — the Electre TRI-NG. Journal of Decision Systems, Paris, v. 21, n. 2, p. 121-136, abr. 2012.

SPICKERMANN, Alexander; GRIENITZ, Volker; VON DER GRACHT, Heiko A. Heading towards a multimodal city of the future? Multi-stakeholder scenarios for urban mobility. Technological Forecasting and Social Change, v. 80, n. 8, p. 1615-1628, 2013.

TEXAS A\&M TRANSPORTATION INSTITUTE. TTI's 2012 Urban mobility report. Texas: The Texas A\&M University System, 2012. p. 1-70.

TRENSURB. História. A Empresa de Trens Urbanos de Porto Alegre S.A, 2013. Disponível em: <www. trensurb.gov.br/paginas/paginas_detalhe.php?codigo_sitemap=48>. Acesso em: 6 abr. 2013.

Jonas Clemente dos Santos é bacharel em administração de empresas pela Universidade Federal de Pernambuco (UFPE). E-mail: jonas_x0@hotmail.com.

Marcos Felipe Falcão Sobral é doutor em engenharia de produção (PPGEP-UFPE). Professor adjunto do Departamento de Administração e do Mestrado em Administração da Universidade Federal Rural de Pernambuco. E-mail: marcos_sobral@bol.com.br. 